\title{
On the mutual interactions of monotonic and cyclic loading and their effect on the strength of aluminium alloys
}

\author{
Z.L. Kowalewski ${ }^{1, a}$, T. Szymczak ${ }^{2, b}$ \\ ${ }^{1}$ Institute of Fundamental Technological Research, \\ ul. Pawinskiego 5B, 02-106 Warszawa, Poland \\ ${ }^{2}$ Motor Transport Institute, ul. Jagiellonska 80, 03-301 Warszawa, Poland \\ azkowalew@ippt.gov.pl, btadeusz.szymczak@its.waw.pl
}

Keywords: cyclic loading, biaxial stress state, softening effect, yield surface.

\begin{abstract}
The paper investigates the interaction of monotonic cyclic loading and their effect on the yield strength of aluminium alloy. Two different loading combinations were considered, i.e. torsion-reverse-torsion superimposed on monotonic tension and monotonic torsion combined with tension-compression cycles. All strain controlled tests were carried out at room temperature using thin-walled tubular specimens. The maximum value of the total cyclic strain amplitude was less than $1 \%$. The influence of amplitude, frequency and shape of cyclic loading signal on the proportional limit and conventional yield point was investigated. The experimental results presented in the paper may be useful to designers of structures that utilize manufacturing processes such as drawing, extrusion, forging of selected semi-finished elements or researchers working on the development of new constitutive equations.
\end{abstract}

\section{Introduction}

In many branches of industry the loading of engineering components is complex and can have an significant influence on the mechanical properties of engineering materials. A typical example of such a situation is a gas rotor turbine, for which three working periods can be distinguished i.e. start-up, operation and switching off [5]. The highest stress values and the largest phase difference between the different components of load are obtained during start-up. Therefore, the start-up is regarded as crucial with respect to variations of the mechanical properties of the material. Since the mechanical parameters of materials can be modified by complex loading many research groups are actually looking at complex loading in an effort to optimize some of the manufacturing processes [1], [2], [3], [4], [6] in order to reduce costs and prolong the lifetimes of engineering components. It can therefore be concluded that knowledge of loading history has at least a twofold role. It is important for adequate choice of materials of structural elements, and moreover, it allows the design of forming processes to guarantee optimal mechanical parameters for particular applications. Hence many mechanical laboratories are involved in such research programmes, which would be able to provide new knowledge related to the influence of complex loading on the selected material parameters of importance in industry.

\section{Details of experimental procedure}

All strain controlled tests were carried out at room temperature under biaxial stress state using thinwalled tubular specimens (Fig. 1) made of the 2024 aluminium alloy commonly used in the aircraft industry. The loading program was designed in such a way that the cyclic loading was superimposed on monotonic deformation, i.e. torsion-reverse-torsion cycles were combined with monotonic tension (Fig. 2), and tension-compression cycles were simultaneously carried out with monotonic torsion (Fig. 3). The total cyclic strain amplitude was less than $1 \%$, since for that magnitude it can 
be assumed that residual stresses are negligible. After the main loading programme a yield surface concept was applied to check if the effects observed during cyclic loading have a permanent character.

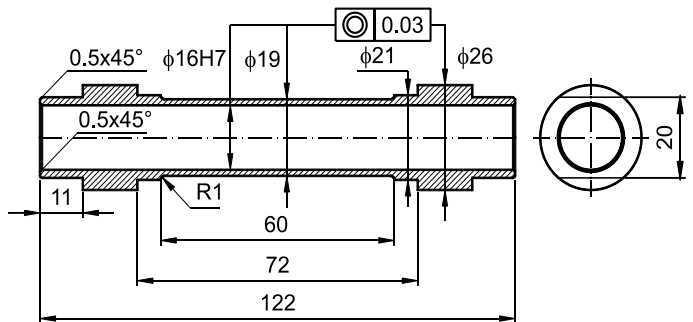

Fig. 1. Dimensions of the biaxially loaded specimen.

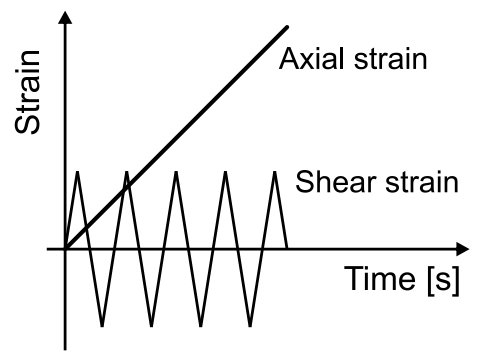

Fig. 2. First loading combination.

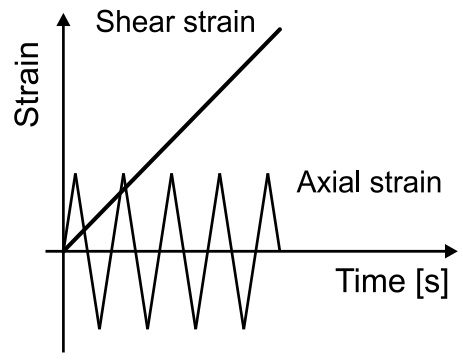

Fig. 3. Second loading combination.

\section{Experimental results}

The influence of torsion-reverse-torsion cycles on the 2024 aluminium alloy behaviour is presented in Fig 4a. The results exhibit a significant lowering of the following mechanical parameters: magnitude of hardening, proportional limit and conventional yield point. The effects are very strong and depend on the amplitude of cyclic loading. An increase of the cyclic strain amplitude led to the further decrease of the stress-strain characteristic. A reduction of the yield point was almost 250 $\mathrm{MPa}$ for a cyclic strain amplitude of $\pm 0.9 \%$.

(a)

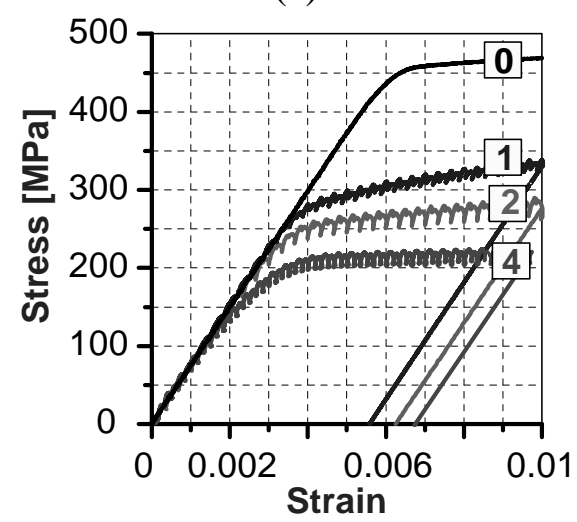

(b)

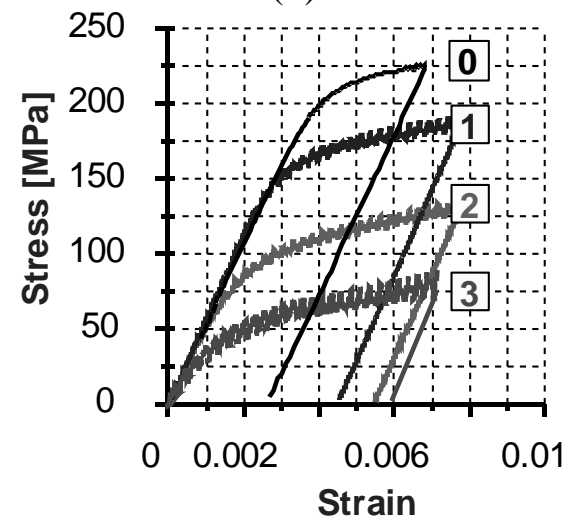

Fig. 4. Tensile (a) and torsional (b) stress-strain characteristics obtained from cyclic loading due to torsion-reverse-torsion and tension-compression, respectively. ( 0 - only monotonic loading, 1-4 with the cyclic loading of strain amplitude equal to $\pm 0.3 \%$ (1), $\pm 0.5 \%$ (2), $\pm 0.7 \%$ (3), $\pm 0.9 \%$ (4)).

A similar effect is observed for the tension-compression cycles superimposed on monotonic torsion, Fig. 4b. This loading regime also caused a significant essential reduction of the yield point. For example, for a cyclic strain amplitude of $\pm 0.7 \%$ the reduction was $170 \mathrm{MPa}$.

In order to confirm the variations of the mechanical parameters observed during the complex loading a yield surface was determined, after unloading of the specimens. If, for example, a reduction of the tensile yield point observed during cyclic loading would be permanent, then such a point on the subsequent yield surface should have a position much closer to the initial yield surface origin. However, as it clearly seen (Fig. 5a, b), this is not the case. The tensile yield point on the subsequent yield loci is even greater then that on the initial yield surface. This means that the reduction of strength during tension in conjunction with cyclic torsion is only temporary. It 
vanishes directly after interruption of cyclic loading. The same tendency can be observed for pure torsion conducted simultaneously with the tension-compression cycles. An increase of the tensile yield point can be attributed to the prior deformation induced by the previous loading history, Fig. 5a. Both diagrams in Fig. 5a, b also illustrate a residual stress evolution. All center points of the subsequent yield surfaces are moved into negative values of the axial stress. Such features identify residual stress variations due to the loading applied.

In conclusion one can say that the comparison of the subsequent yield loci with the initial yield surface exhibits only an influence of the loading history applied, and moreover, proves a transient character of the stress drop in a direction of the monotonic loading, which can be solely attributed to cycles acting in the perpendicular direction.

(a)

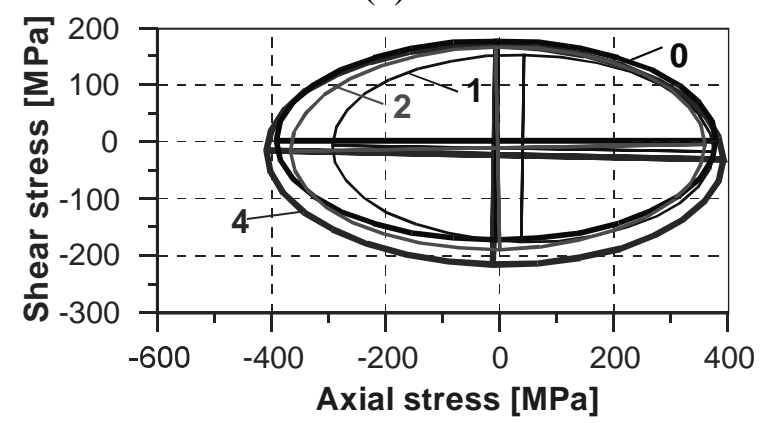

(b)

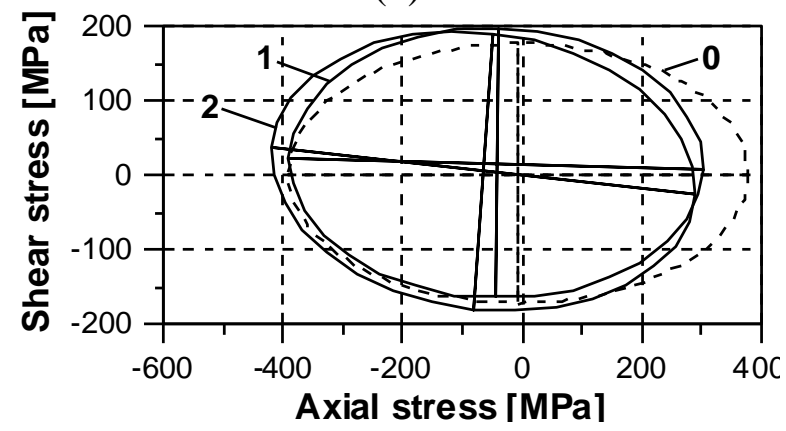

Fig. 5. An initial yield surface (0) evolution due to the presence of torsion-reverse-torsion cycles (a) or tension-compression cycles (b) during monotonic deformation by tension or torsion, respectively.

Numbers 1, 2, 4 correspond to magnitudes of strain amplitude of $\pm 0.3 \%, \pm 0.5 \%, \pm 0.9 \%$, respectively.

(a)

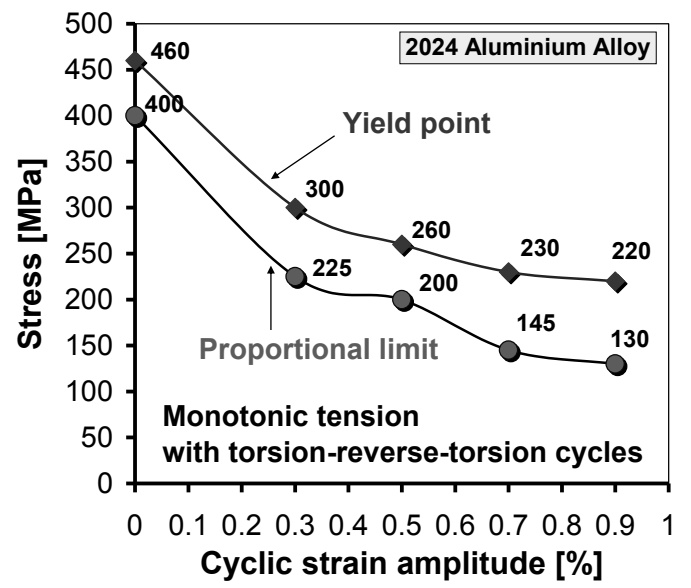

(b)

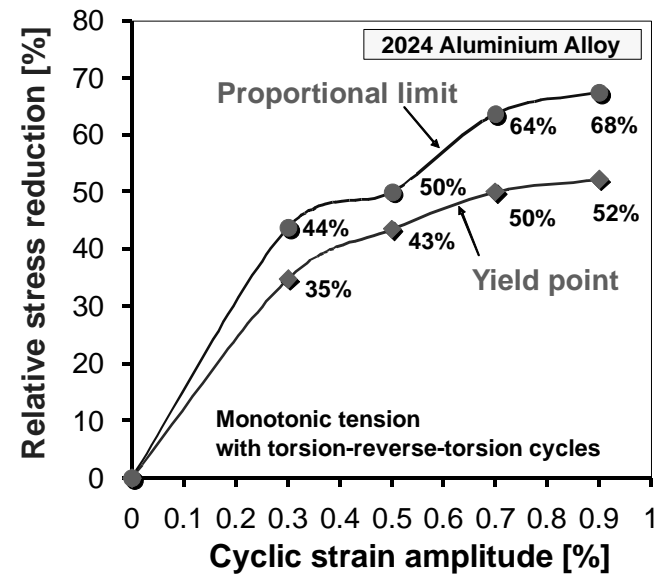

Fig. 6. Diagrams reflecting variations of the yield point and proportional limit for combined monotonic tension and torsion cycles for different strain amplitudes.

In the next stage of the experimental programme further variations of mechanical parameters were investigated. The representative results are presented in Fig. 6a, b. The figure illustrates a reduction of stress parameters due to the presence of the combined cyclic and monotonic loading shown in Fig. 2. For the highest cyclic strain amplitude $( \pm 0.9 \%)$ the reduction of the proportional limit and yield point are $70 \%$ and $50 \%$, respectively. In the case of the second loading programme, a combination of monotonic torsion and tension-compression cycles (Fig. 3), the yield point decreases from 223MPa to $63 \mathrm{MPa}$, a $72 \%$ reduction, see Fig. 7a, b. The significant lowering of the 
magnitude of the hardening curve and the conventional mechanical parameters may play a role in the modification of some manufacturing processes, because it enables a reduction of the force applied during forging or extrusion processes for example. From a theoretical point of view such knowledge is essential for the development of new constitutive equations.

(a)

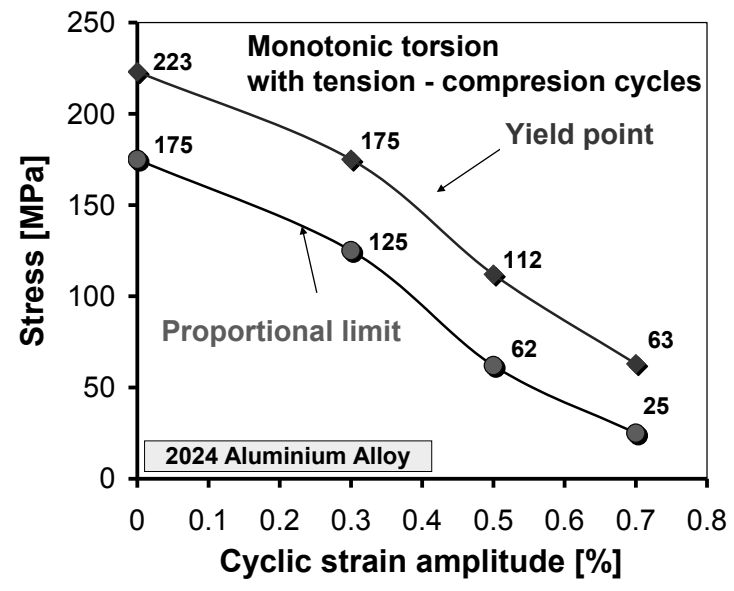

(b)

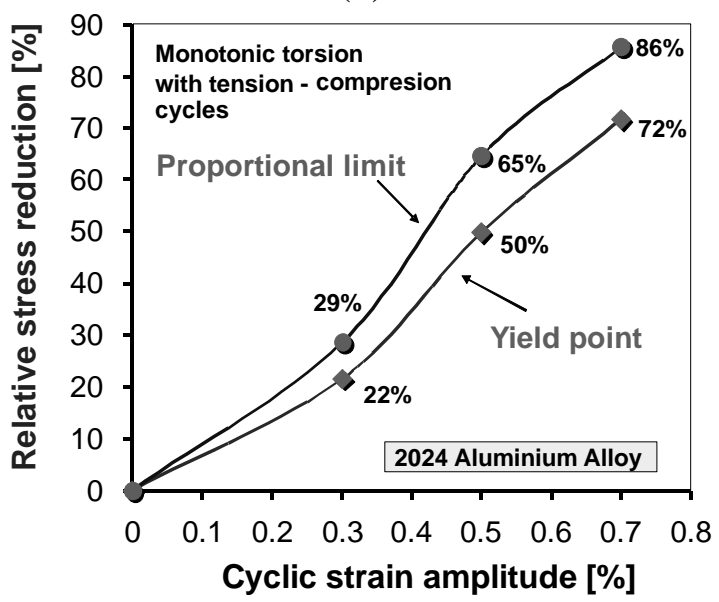

Fig. 7. Diagrams reflecting variations of the yield point and proportional limit for combined monotonic torsion and tension-compression cycles for different strain amplitudes.

From the results of these tests it is clear that cyclic loading superimposed on monotonic loading leads to significant reduction of the aluminium strength. This phenomenon could be beneficial for many industrial applications. Energy balance calculations have been performed to compare plastic strain energy dissipated during a typical monotonic test and that of a monotonic-cyclic loading combination. The results are summarized in Tab. 1 and illustrated in Fig. 8.

Table 1. Variations of the total plastic strain energy during monotonic deformation assisted by torsion-reverse-torsion cycles.

\begin{tabular}{|c|c|c|c|c|c|}
\hline $\mathbf{A}$ & B & C & D & $\mathbf{E}$ & $\mathbf{F}$ \\
\hline $\begin{array}{l}\text { Plastic Strain } \\
\text { Energy for } \\
\text { Monotonic } \\
\text { Tension } \\
{\left[\mathrm{MJ} / \mathrm{m}^{3}\right]}\end{array}$ & $\begin{array}{c}\text { Cyclic Strain } \\
\text { Amplitude } \\
{[\%]}\end{array}$ & & $\begin{array}{c}\text { Monotonic } \\
\text { Tension assisted } \\
\text { by Torsion- } \\
\text { Reverse-Torsion } \\
\text { for } 20 \text { cycles }\end{array}$ & $\begin{array}{l}\text { Torsion-Reverse- } \\
\text { Torsion for } 20 \\
\text { cycles }\end{array}$ & $\begin{array}{c}\text { Total Plastic } \\
\text { Strain Energy for } \\
\text { Monotonic-Cyclic } \\
\text { Loading }\left[\mathrm{MJ} / \mathrm{m}^{3}\right]\end{array}$ \\
\hline \multirow{4}{*}{1.7} & 0.0 & \multirow{4}{*}{$\begin{array}{l}\text { Plastic energy } \\
{\left[\mathrm{MJ} / \mathbf{m}^{3}\right]}\end{array}$} & & & 1.7 \\
\hline & 0.3 & & 1.0 & 0.0 & 1.0 \\
\hline & 0.5 & & 0.9 & 5.0 & 5.9 \\
\hline & 0.9 & & 0.7 & 38.2 & 38.8 \\
\hline
\end{tabular}

The total plastic strain energy dissipated during uniaxial tension is reduced by a factor of $40 \%$ in comparison to the same type of loading assisted by torsion cycles conducted for the lowest magnitude of strain amplitude considered $(0.3 \%)$ in the programme. For greater cyclic strain amplitudes the total plastic strain energy increases, and therefore, these cases are not so beneficial by accounting for the energy balance. Despite of the total strain energy increasing with an increase of the cyclic strain amplitude we have to remember that superimposing cyclic loading on monotonic 
loading reduces the stress parameters significantly. In many industrial applications this reduction would extend the lifetimes of some engineering components. This is especially important when considering the manufacturing costs of these elements which are extremely high.

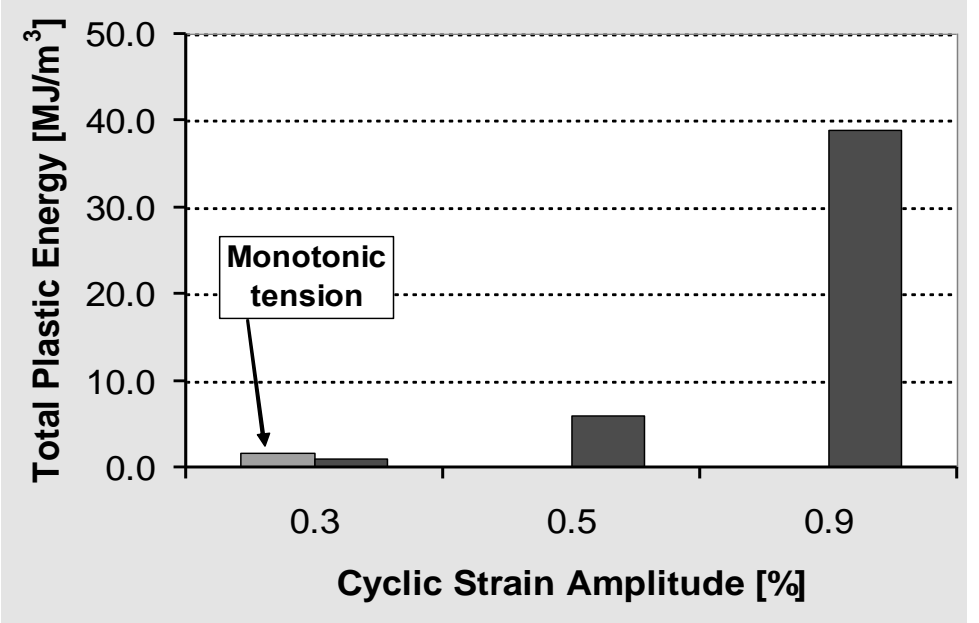

Fig. 8. Illustration of the total plastic strain energy for uniaxial tension up to a maximum strain of $1 \%$, and a combination of monotonic tension up to a maximum strain of $1 \%$ with torsion cycles of different strain amplitudes.

\section{Remarks and conclusions}

The paper emphasizes the role of cyclic loading superimposed on monotonic loading and its effect on the strength of aluminium alloy. The results allow the following concluding remarks to be made:

- cyclic loading in combination with monotonic loading may cause a significant lowering of the proportional limit and conventional yield point,

- an increase of cyclic strain amplitude decreases the proportional limit and yield point,

- the decrease in the mechanical properties is not permanent and after termination of cyclic loading it vanishes and the material properties return to the initial values,

- cyclic loading due to tension-compression and torsion-reverse-torsion cycles in combination with monotonic loading by tension and torsion, respectively, slightly modifies the magnitude of the residual stresses,

- an initial yield surface evolution does not confirm the rapid reduction of the selected mechanical parameters during monotonic loading assisted by cyclic loading, it only points out their variations due to the loading history applied.

In order to gain a more thorough knowledge of the effects presented in this paper microscopic observations are necessary. They should be carrying out "on line" with the loading process. The stress reduction observed during tests can be treated as an important factor for modification of any manufacturing processes that are a combination of monotonic and cyclic loading. The applied loading combinations considered give a promising tool for reduction of the plastic strain energy demand, and moreover, ensure more beneficial working conditions leading to the lifetime extension of some working elements of machines used to fabricate many products in the form of rods, tubes, etc. 


\section{References}

[1] W. Bochniak, A. Korbel, R. Szyndler, R. Hanarz, F. Stalony-Dobrzański, L. Błaż, P. Starski: J. Mat. Proc. Tech., Vol. 173, (2006), p. 75.

[2] W. Bochniak, A. Korbel, R. Szyndler: Innovative solutions for metal forming, Proc. Inter. Conf. MEFORM 2001 - Herstellung von Rohren und Profilen, Institut für Metallformung Tagungsband, 239, Freiberg/Riesa, 2001.

[3] L.X. Kong, P.D. Hodgson: Mater. Sci. Eng., A 276, (2000), p. 32.

[4] A. Korbel, W. Bochniak: J. Mater. Proc. Tech., 53, (1995), p. 229.

[5] C. Michaelsen, W. Hoffelner: The role of state of stress for the determination of the lifetime of turbine components, Fatigue under Biaxial and Multiaxial Loading, Mechanical Engineering Publication, London, 53-63, 1991.

[6] G. Niewielski, D. Kuc, K. Rodak, F. Grosman, J. Pawlicki: Journal of Achievements in Materials and Manufacturing Engineering, 17, 1-2, (2006), p.109. 